\title{
Pediatricians push for public coverage of contraceptives for youth
}

Cite as: CMAJ 2019 May 27;191:E593-4. doi: 10.1503/cmaj.109-5756

Posted on cmajnews.com on May 9, 2019.

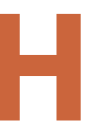

igh costs and concerns about confidentiality remain major barriers to young Canadians using contraceptives, pediatricians warn. In a new statement, the Canadian Paediatric Society (CPS) is calling for confidential public coverage of all contraceptives for youth up to age 25 .

"Having an unplanned pregnancy can really derail your life," particularly at younger ages, says Dr. Giosi Di Meglio, a Montreal-based adolescent medicine specialist and an author of the statement. "All women should have access to contraception at low or no cost, but we need to do it urgently for kids who are most vulnerable."

More than a quarter of Canadian youth do not use contraceptives consistently. The CPS recommends that they use the most effective long-acting reversible contraceptives, such as intrauterine devices (IUDs). But young people who are interested in these methods often end up using less reliable methods because of the cost, Di Meglio says. Hormonal IUDs can cost hundreds of dollars upfront. Even $\$ 10$ to $\$ 15$ for oral contraceptives "can be a challenge for a young person."

Meanwhile, youth who have private insurance through their families may feel uncomfortable claiming the cost because their parents will be notified of the transaction. In one case, a young woman resorted to using condoms while she secretly saved up for an IUD. She eventually got help from her mother, who agreed it would be unsafe for her father to know.

"We routinely run into kids who are either not contracepting at all or who are using withdrawal," rather than risk their parents finding out they're using contraceptives, Di Meglio says.

Many providers will try to find workarounds when young patients can't afford birth control. However, Di Meglio argues that's not a good system because it "depends on people begging," and many patients won't ask for contraception if they know they can't afford it.

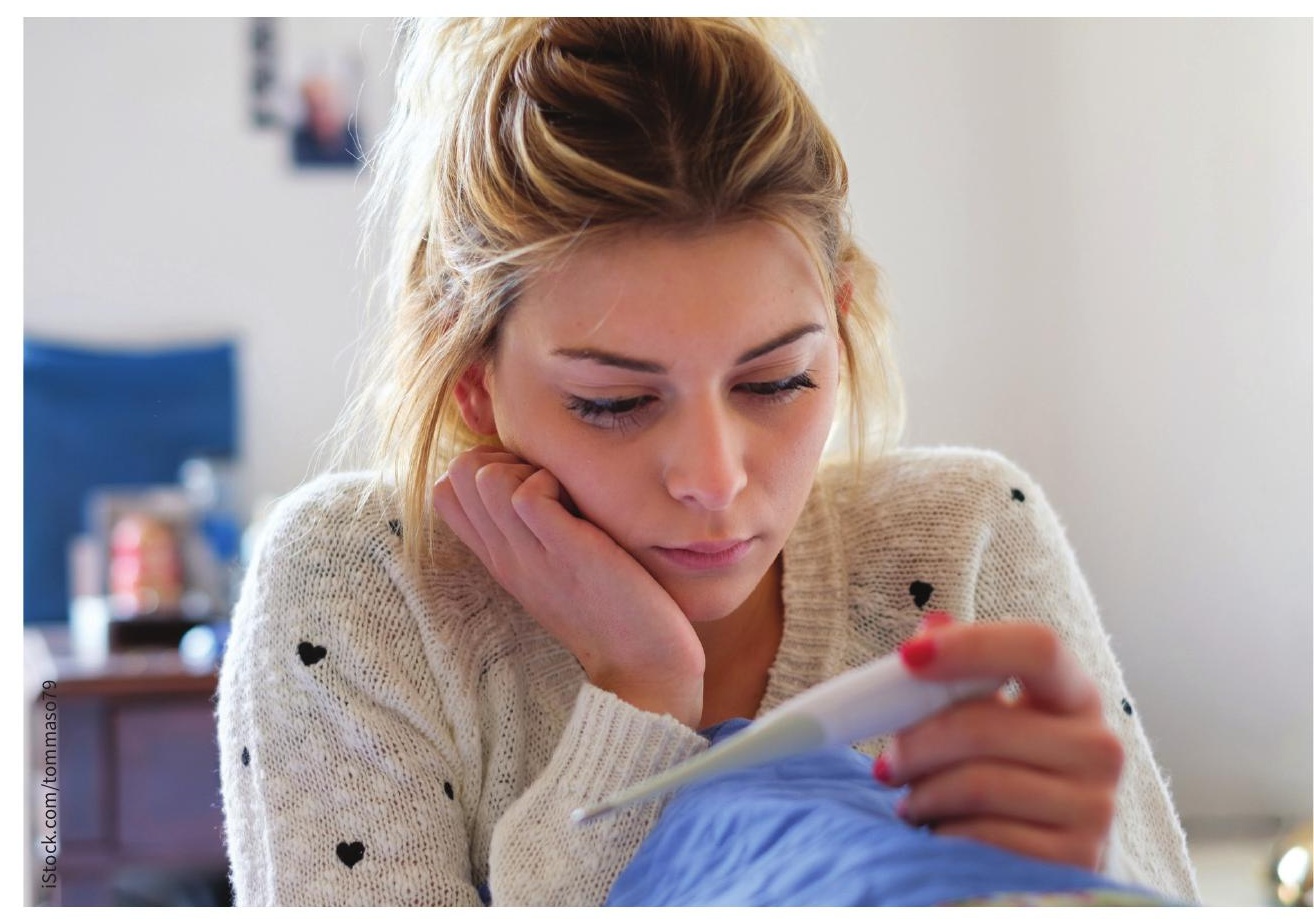

More than a quarter of young Canadians do not use contraceptives consistently, often because of the cost.

Improving access is particularly important as more Canadian women are opting for less effective methods and using them less consistently than a decade ago. Condoms and "pulling out," along with the pill, are still the most popular methods of birth control among Canadian women, according to the Society of Obstetricians and Gynaecologists of Canada (SOGC). Reliance on condoms alone increased across all age groups between 2006 and 2016, with a marked uptick among teens from $21 \%$ to $50.1 \%$.

According to Dr. Amanda Black of the SOGC's Contraception Awareness Program Working Group, "it's concerning 
to prevent pregnancy, up from less than 1 in 20 in 2006.

Ignorance about contraceptive options, increasing concerns about adverse effects and eroding trust in health providers may be driving these trends. But according to Di Meglio, studies show offering contraceptives for free increases uptake.

It makes good economic sense, too, she says. A 2015 study estimated the cost of covering contraception for all Canadian women would be repaid more than twofold by savings on medical costs associ- ated with unplanned pregnancies. But based on the experiences of other countries, the return on investment "may be closer to 7:1," Di Meglio says. "This is a cheap intervention that benefits all of us."

Lauren Vogel, CMAJ 